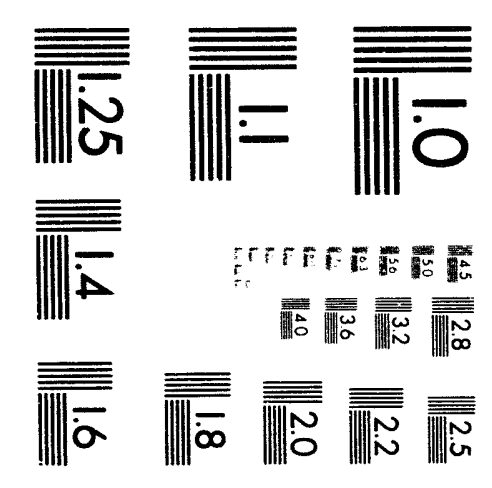



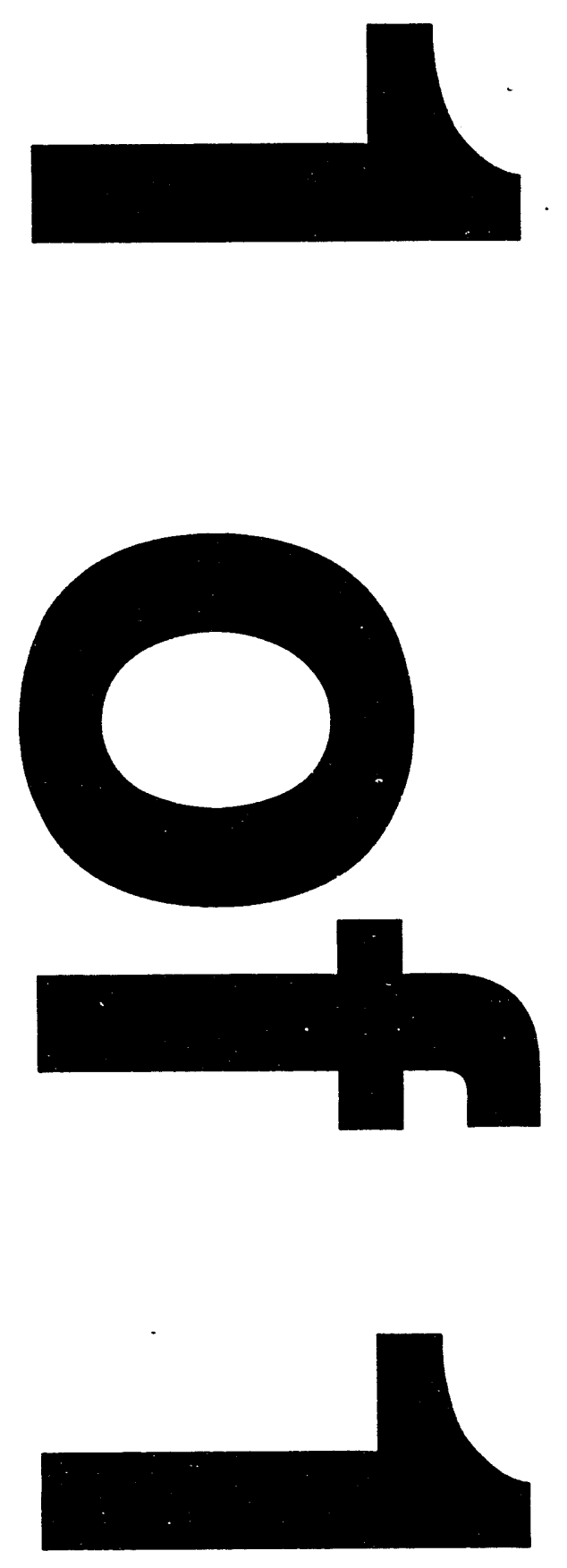


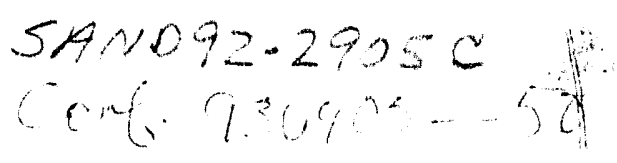

\title{
ORIENTED LEAD ZIRCONATE TITANATE THIN FILMS: CHARACTERIZATION OF FILM CRYSTALLIZATION
}

\author{
JAMES A. VOIGT, B. A. TUTTLE, T. J. HEADLEY, M. O. EATOUGH, D. L. LAMPPA, \\ AND D. GOODNOW \\ Sandia National Laboratories, P.O. Box 5800, Albuquerque, NM 87185.
}

\begin{abstract}
Through systematic variation of film processing temperature and time, we have characterized the pyrochlore to perovskite crystallization process of solution-derived PZT 20/80 thin films. The $\approx 3000 \AA$ thick films were prepared by spin deposition using $<100>$ single crystal $\mathrm{MgO}$ as the film substrate. By controlled rapid thermal processing, films at different stages in the perovskite crystallization process were prepared with the tetragonal PZT 20/80 phase being $<100>\mid<001>$ oriented relative to the $\mathrm{MgO}$ surface. An activation energy for the conversion process of $326 \mathrm{~kJ} / \mathrm{mole}$ was determined by use of an Arrhenius expression using rate constants found by application of the method of Avrami. The activation energy for formation of the PZT 20/80 perovskite phase of the solution-derived films compared favorably with that calculated from data by Kwok and Desu [1] for sputter-deposited $3500 \AA$ thick PZT 55/45 films. The similarity in activation energies indicates that the energetics of the conversion process are not strongly dependent on the method used for film deposition.
\end{abstract}

\section{INTRODUCTION}

The ability to control the microstructural properties of ferroelectric (FE) thin films is of critical importance to many applications. In nonvolatile memory applications, for example, the grain size in the polycrystalline FE film should be substantially smaller than device feature sizes to insure uniform electrical performance throughout the memory. Although recently the characterization of FE film microstructures has been the subject of much study [2], relatively' little work has been done to develop an understanding of the nucleation and growth processes involved in the formation of the FE perovskite phase $[1,3,4]$.

Most FE films are prepared by first depositing a precursor film containing constituent metal ions in the desired stoichiometry using a standard film deposition technique, such as chemical vapor deposition or solution coating. The precursor film, which can be amorphous as deposited, is then often converted to the crystalline desired FE phase by a thermal processing operation. For the lead zirconate titanate, PZT, system, it is well documented that the FE perovskite phase crystallizes out of a nanocrystalline pyrochlore matrix that forms during the initial stages (low temperatures) of the thermal processing step [5-7]. The resulting microstructure of the FE PZT film is drariatically influenced by the zirconium to titanium ratio $[5,8]$. Films with a high zirconium content tend to form large perovskite grain structures (on the size scale of several microns) that are often called rosettes due to their resemblance to spherulitically grown particles. Titanium rich films, on the other hand, typically have much smaller, often submicron grain sizes indicating much higher nucleation rates. Other factors, including precursor film structure $[6,9]$ and the substrate material [10], can also influence film microstructure. As an example for the film preparation process used in this study, PZT films prepared and processed identically' (i.e.. $<100>\mathrm{MgO}$ substrates, processecd at $650^{\circ} \mathrm{C}$ for $10 \mathrm{~min}$ in flowing oxygen) but with zirconium to titanium ratios of 40:60 and 20:80 had average grain sizes of $2 \mu \mathrm{m} / 10]$ and $0.7 \mu \mathrm{m}$, respectively, as determined by the lineal intercept method using a multiplicative factor of 1 .

In this paper, we describe initial results of our work on characterizing the conversion of solution-derived PZT thin films from the nanocrystalline pyrochlore phase to the perovskite phase. A high titanium content composition (PZ̈T 20/80) was chosen in order to study the crystallization process when nucleation rates are higher and finer grained microstructures are produced than for near-morphotropic phase boundary compositions. Single crystal MgO substrates were used so that the processes involved in the formation of oriented PZT films could

*This work was performed at Sandia National taboratories, supported by the Department of Energy under Contract \# DE-AC04-94AL85000. 


\section{DISCLAIMER}

This report was prepared as an account of work sponsored by an agency of the United States Government. Neither the United States Government nor any agency thereof, nor any of their employees, makes any warranty, express or implied, or assumes any legal liability or responsibility for the accuracy, completeness, or usefulness of any information, apparatus, product, or process disclosed, or represents that its use would not infringe privately owned rights. Reference herein to any specific commercial product, process, or service by trade name, trademark, manufacturer, or otherwise does not necessarily constitute or imply its endorsement, recommendation, or favoring by the United States Governr ent or any agency thereof. The views and opinions of authors expressed herein do not necessarily state or reflect those of the United States Government or any agency thereof. 
be investigated. Also, the tetragonal form of the PZT 20/80 phase allowed us to readily characterize ferroelectric domain structure as a function of film processing conditions [11]. Finally, our results on high titanium, solution-derived PZT thin films could be compared with work by Kwok and Desu [1] on the kinetics of the conversion of sputter-deposited PZT thin films near the morphotropic phase boundary (PZT 55/45).

\section{EXPERIMENTAL}

PZT 20/80 films were fabricated by spin-coating (3000 $\mathrm{rpm}$ for 30 seconds) using a solution prepared by the inverted mixing order process developed by Schwartz et al. [12] which is a modification of a hybrid solution deposition process developed by Sayer and coworkers [13]. Excess lead (5 mole \%) was added to be consistent with previous work on preparation of oriented PZT films $[10,14]$. To obtain oriented growth, $<100\rangle$ single crystal $\mathrm{MgO}$ with an epitaxial surface finish was used as the substrate. The substrates were heat treated at $400^{\circ} \mathrm{C}$ in air for 10 minutes prior to film deposition. Films were decomposed using a 5 minute heat treatment at $300^{\circ} \mathrm{C}$ on a hot plate. Three film layers were deposited to produce films with a thickness of $\approx 3000 \AA$. Film crystallization was carried out using a rapid thermal processing, RTP, system (AET/Addax, Model RMV4, Milpitas, CA). For a more detailed discussion of the film preparation process see Tuttle et al. [10].

\section{RESULTS AND DISCUSSION}

We have used rapid thermal processing to obtain thin films at different stages of conversion to the PZT 20/80 perovskite phase. Figure 1 shows thermal cycles used for processing films at $500^{\circ} \mathrm{C}$ for $30 \mathrm{sec}$ and $10 \mathrm{~min}$. Within the constraints of the RTP system software, the heating rate was programmed to be as close to $160^{\circ} \mathrm{C} / \mathrm{sec}$ as possible for all of the thermal processing cycles used in this study. In general, the film surface reached the programmed soak temperature within six seconds of the programmed time with little or no over shoot as measured by the temperature controlling thermocouple located on the film surface. Sample cooling varied depending on processing temperature and time (see Figure 1) due to the thermal mass of the quartz furnace chamber of the RTP system. All samples, however, cooled through the PZT $20 / 80$ Curie temperature $\left(\approx 450^{\circ} \mathrm{C}\right)$ at a relatively constant rate of $8^{\circ} \mathrm{C} / \mathrm{sec}$ regardless of the processing condition.

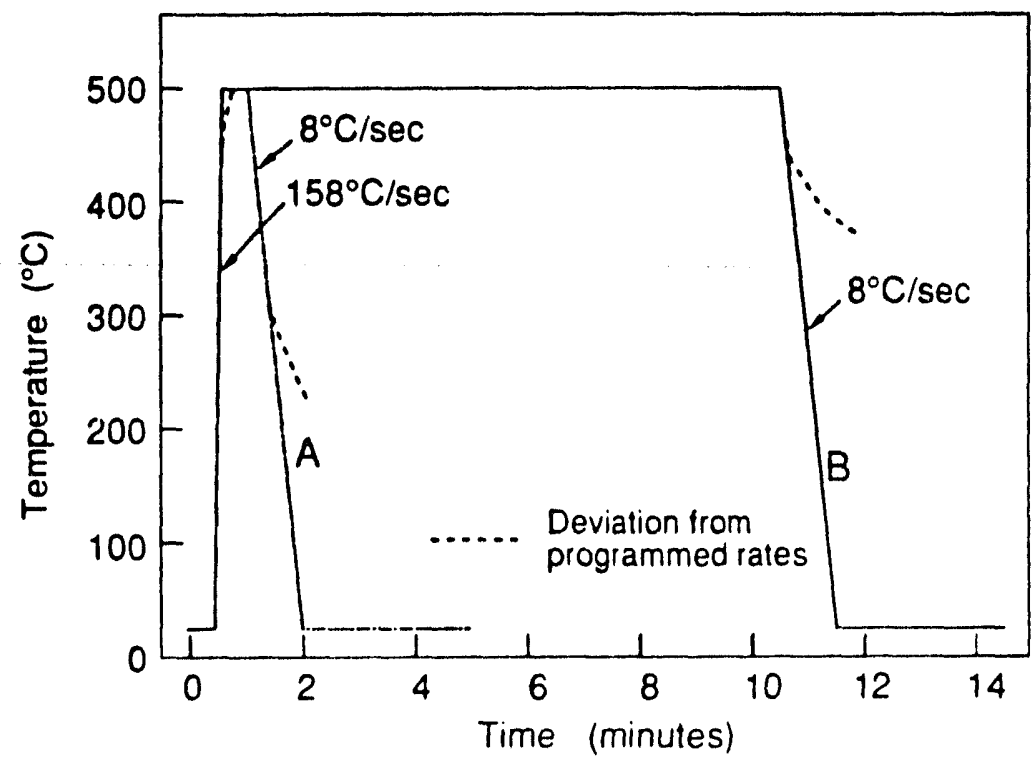

Fig. 1. Rapid thermal processing (RTP) schedules including deviations from programmed temperatures: A) $500^{\circ} \mathrm{C}$ for $30 \mathrm{~s}$, and $\mathrm{B}) 500^{\circ} \mathrm{C}$ for $600 \mathrm{~s}$.

As has been discussed earlier, the perovskite phase forms by a solid state conversiun of a nanocrystalline pyrochlore phase that forms rapidly during film heating at temperatures above $400^{\circ} \mathrm{C}$. This is illustrated in Figure 2 where $x$-ray diffraction results for films processed using the heating schedules in Figure 1 are shown. The $x$-ray results show that the film processed at $500^{\circ} \mathrm{C}$ for $30 \mathrm{sec}$ is mainly the pyrochlore phase with only a trace amount of perovskite present. After $10 \mathrm{~min}$ at $500^{\circ} \mathrm{C}$ the $\mathrm{x}$-ray diffraction results show that the film has been fully converted to a highly $<001>1<100>$ oriented perovskite. The high degree of orientation is shown by the low 


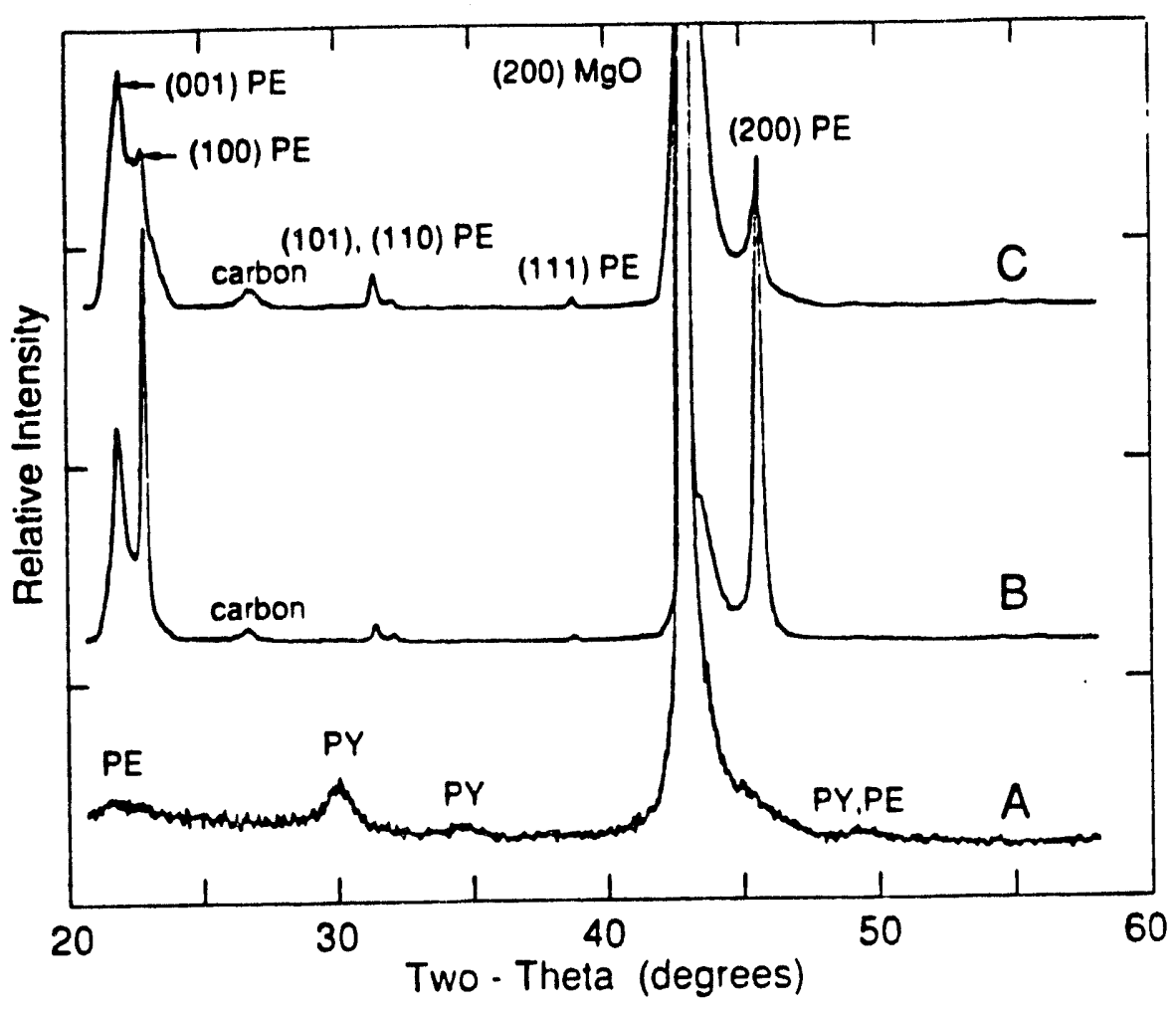

Fig. 2. X-ray diffraction patterns of $\approx 300$-nm-thick PZT $20 / 80$ films on $<100>$ single crystal $\mathrm{MgO}$ processed under the following conditions: $\mathrm{A}$ ) $500^{\circ} \mathrm{C}, 30 \mathrm{~s}$ (intensity is $\times 5$ ), B) $500^{\circ} \mathrm{C}, 600 \mathrm{~s}$, and C) $550^{\circ} \mathrm{C}, 30 \mathrm{~s}(\mathrm{PE}=$ perovskite, $\mathrm{PY}=$ pyrochlore, carbon presence due to prior SEM analysis).

intensity of the normally major $\langle 110\rangle$ diffraction peak. The splitting of the $\langle 001\rangle$ and $\langle 100\rangle$ peaks is expected due to the tetragonal structure of the PZT 20/80 phase. The much greater intensity of the $<100\rangle$ diffraction peak relative to that of the $<001>$ peak is due to the film/ $/ \mathrm{MgO}$ stress relationship as the film cools through the Curie point [14].

The extreme temperature sensitivity of the pyrochlore to perovskite transformation is-shewin by comparison of the $\mathrm{x}$-ray diffraction results for a film processed at $550^{\circ} \mathrm{C}$ for $30 \mathrm{sec}$ (Figure 2) to those already discussed that were processed at $500^{\circ} \mathrm{C}$. After 30 seconds at $550^{\circ} \mathrm{C}$ the film is completely converted to perovskite whereas it took approximately 10 minutes at $500^{\circ} \mathrm{C}$ to get the same level of conversion, as determined by $x$-ray diffraction. Kinetic information on the pyrochlore/perovskite transformation only could be obtained up to $525^{\circ} \mathrm{C}$; above this temperature the transformation was too fast to be accurately controlled by the RTP system. The fast kinetics of the transformation process at moderate temperatures is related to the high titanium content of the films used in this study. For comparison, Kwok and Desu [1] show $\mathrm{x}$-ray results for the conversion of sputter-deposited PZT 55/45 films in which a significant amount of pyrochlore remains even after $15 \min$ at $550^{\circ} \mathrm{C}$.

Figure 3 is a backscattered electron, BSE, photomicrograph of a partially transformed PZT $20 / 80$ film. The high contrast between the perovskite phase (lighter) and the pyrochlore phase (darker) results from the density difference between the two phases. The higher density of the perovskite phase causes a higher flux of backscattered electrons resulting in a brighter BSE image. The figure shows the characteristic circular single crystal perovskite grains that grow out of the pyrochlore matrix. The single crystal form of these grains is shown more clearly using plan view transmission electron microscopy as illustrated in Figure 4 . The domain structure within the perovskite grains are easily seen as is the uniform fine scale structure of the pyrochlore matrix material. It should be noted that the pyrochlore matrix consisted of a single nanocrystalline phase; in contrast to the diphasic pyrochlore matrix that has been reported for films with higher zirconium to titanium ratios [5,7]. 


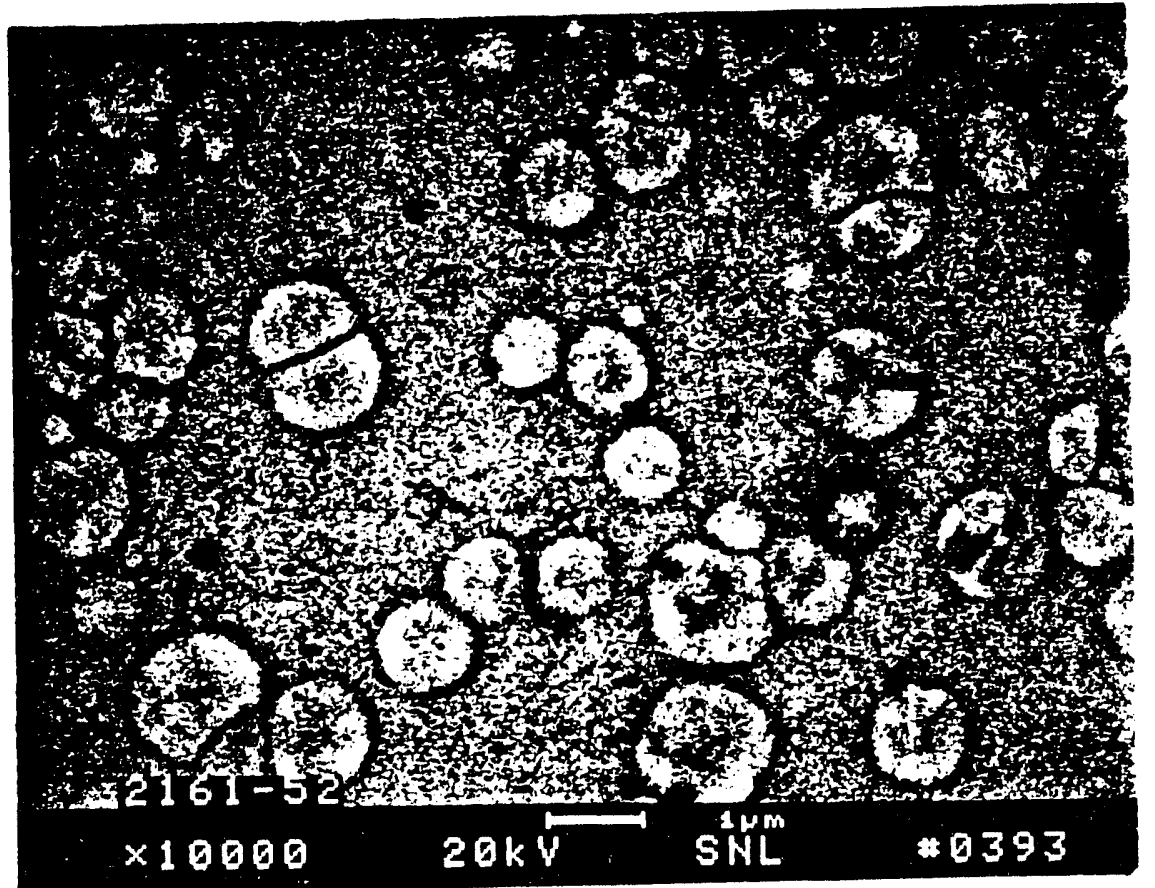

Fig. 3. Back scattered electron (BSE) photomicrograph of oriented PZT 20/80 thin film processed for $60 \mathrm{~s}$ at $525^{\circ} \mathrm{C}$ (lighter regions are circular, single crystal perovskite grains growing out of pyrochlore matrix).

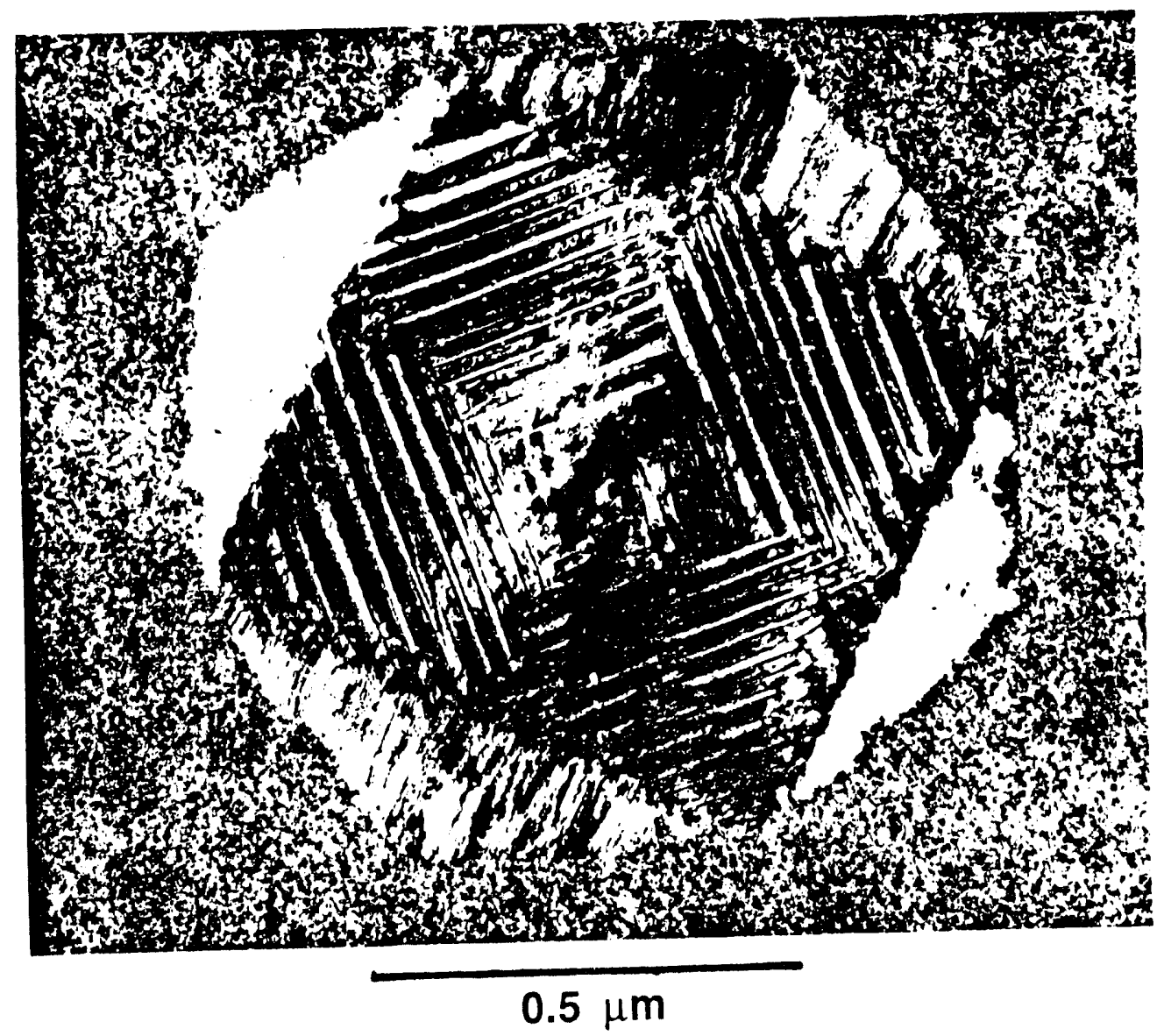

Fig. 4. Bright-field transmission electron photomicrograph of typical perovskite single crystal grain that has grown out of pyrochlore matrix dirino P7.T 20/80 crvstallization process. 
The transformation process was characterized at a constant temperature, $T$, by application of the Johnson-Mehl-Avrami equation [15,16],

$$
X(t)=1-\exp \left[-(K t)^{N}\right]
$$

where $X(t)$ is the volume fraction of perovskite formed after time,t, $K$ is the rate constant , and $N$ is the growth exponent. Image analysis of BSE photomicrographs was used to determine $X(t)$. It was assumed that the area fraction determined by image analysis was equal to a film's volume fraction of perovskite. Because of limitations in resolution of the BSE images and the error introduced in assuming that the perovskite phase is uniformly distributed throughout the thickness of the film, the results of the use of the Avrami method to analyze the conversion process are somewhat qualitative. Taking the $\log$ of equation 1 twice results in a linear expression where the slope and the $y$ intercept are equal to $\mathrm{N}$ and $\mathrm{N} \ln (\mathrm{K})$, respectively, when $\ln \{\ln [1 /(1-X)]\}$ is plotted versus $\ln (t)$. Figure 5 shows such a plot for films processed at 475,500 , and $525^{\circ} \mathrm{C}$. The data show the expected linear relationship with an average growth exponent of 2.04 .

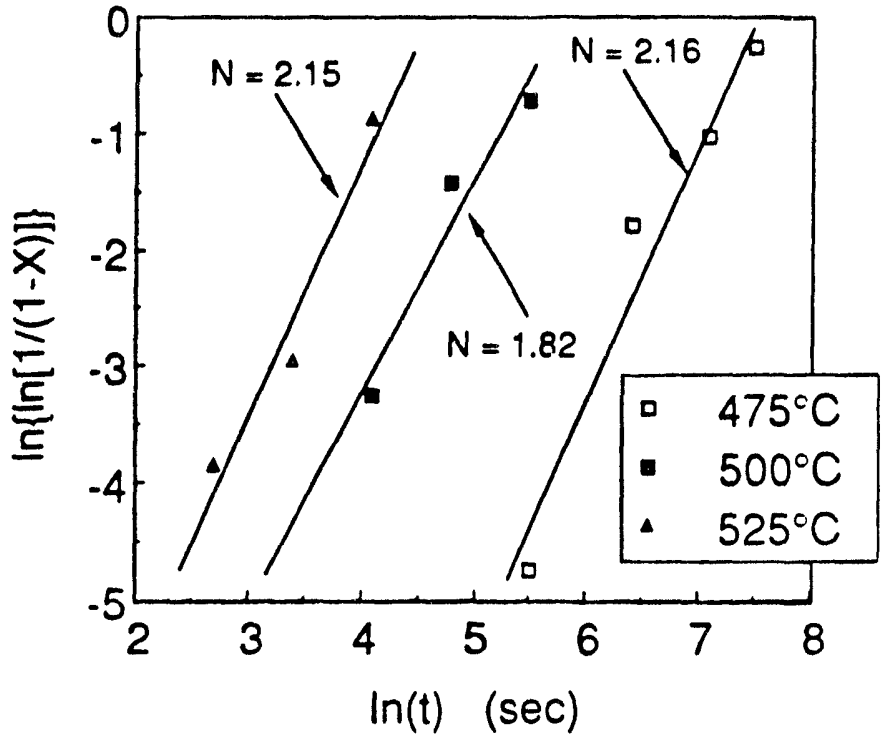

Fig. 5. Plot of $\ln \{\ln [1 /(1-X)]\}$ vs. $\ln (t)$. This value is similar to that found for sputter-deposited PZT 55/45 thin films $\left(\mathrm{N}_{\mathrm{ave}}=2.23\right)$ [1] and also for the crystallization of sol gel-derived titania thin films $\left(\mathrm{N}_{\mathrm{ave}}=1.76\right)$ [17].

The rate constants determined by the Avrami analysis were used to calculate an overall activation energy, $\mathrm{E}_{\mathrm{a}}$, for the solid state phase transformation using the Arrhenius expression,

$$
K=A \exp \left(-E_{2} / k T\right)
$$

where $\mathrm{k}$ is Boltzmann's constant and $A$ is related to the activation entropy for the process [18]. A value of 326 $\mathrm{kJ} / \mathrm{mole}$ was found for the activation energy from the linear relationship shown in Figure 6. Again, this is in reasonable agreement with the data of Kwich and Desu on sputter-deposited PZT 55/45 [1], where an $E_{a}$ of 248 $\mathrm{kJ} / \mathrm{mole}$ was calculated using equations 1 and 2. For comparison, Shaikh and Vest found an activation energy of about $84 \mathrm{~kJ} / \mathrm{mole}$ for the formation of $\mathrm{PbTiO}_{3}$ powder from organometallic precursors [19].

A difference in overal! activation energies for the PZT 20/80 and PZT $55 / 45$ thin films can be expected for several reasons. The overall activation energy for crystallization is a function of the activation energies

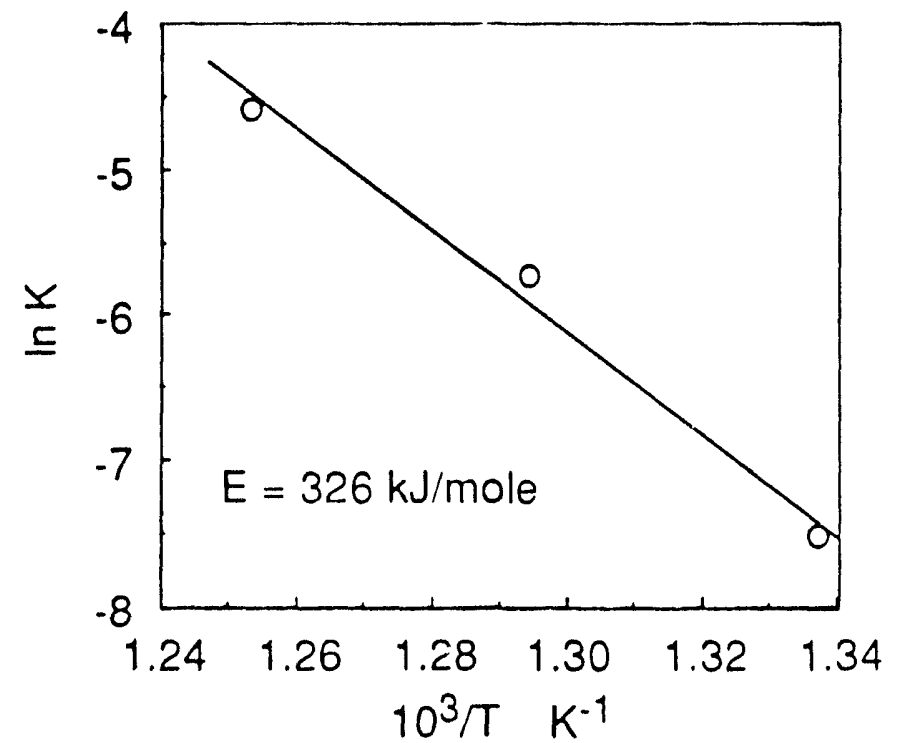

Fig. 6. The inverse temperature dependence of the rate constant $\mathrm{K}$. 
of nucleation and growth. The functional form of this relationship is dependent on the mode of the transformation (e.g., $E_{a}=E_{\text {nucleation }}+(N-1) E_{\text {growth }}$ for constant nucleation rate and linear two-dimensional growth) [20]. As discussed earfier, the zirconium to titanium ratio strongly influences the perovskite nucleation and growth processes. These observations indicate that the energetics of the nucleation and growth processes, and thus the overall activation energy for erystallization, should be dependent on composition. The effect of composition on the activation energy of thin film crystallization has been shown previously for the crystallization of amorphous $\mathrm{Ge} / \mathrm{Si}$ films on $\mathrm{SiO}_{2}$ by Edelman and coworkers [21]. They found that $\mathrm{E}_{\mathrm{a}}$ varied for $\mathrm{Ge}_{\mathrm{x}} \mathrm{Si}_{1-\mathrm{x}}$ from $299 \mathrm{~kJ} / \mathrm{mole}$ to $193 \mathrm{~kJ} / \mathrm{mole}$ for $x$ going from 1 to 0 where $E_{a}$ was calculated based on the induction time for nucleation. It is expected that $E_{a}$ for PZT thin films should decrease with increasing titanium content. This conclusion is based on previous observations that nucleation rates increase with increasing titanium and, also, by the fact that the kinetics of the conversion for the PZT 20/80 films was faster than that of the PZT 55/45 films for a fixed temperature (see discussion of $\mathrm{X}$-ray diffraction results). Unfortunately that is the opposite of what is reported here. The inconsitstency is no doubt related to the inaccuracy in the method used to determine the volume fraction of perovskite which was the same for both studies discussed here. For example, the activation energies are statistically the same if an error of only about $15 \%$ is assumed. The fact that different film deposition methods (solution versus sputtering) and substrates ( $<100>\mathrm{MgO}$ versus $\mathrm{Pt}$ coated single crystal $\mathrm{Si}$ ) were used in the two studies also makes direct comparisons difficult.

\section{SUMMARY}

The overall activation energy for the solid state transformation of nanocrystalline pyrochlore to perovskite for solution-derived PZT 20/80 thin films was deterimined. The value is in reasonable agrecment with previously published data on sputter-deposited PZT 55/45 thin films. This result indicates that the energetics of the transformation process are not greatly different despite the differences in deposition method, substrate material, and composition. In order to do a quantitative comparison of the effect of these variables on the conversion kinetics, a more accurate technique is required to determine the fraction of film converted to the perovskite phase. Our results on the microstructural development of the perovskite phase in PZT 20/80 thin films in terms of nucleation and growth will be presented in a future publication.

\section{ACKNOWLEDGEMENTS}

We would like to thank B. McKenzie (SEM), F. A. Greulich (image analysis), A. Kilgo (image analysis), M. Gonzales (x-ray diffraction), and T. Tribble (TEM sample preparation) for their contitiutions to this project.

\section{REFERENCES}

1. C. K. Kwok and S. B. Desu in Ferroelectric Films, edited by A. S. Bhalla and K. M. Nair -(Ceram. Trans. 25, Amer. Ceram. Soc.,Westerville, OH, 1992) pp.85-96.

2. (a) Ferroelectric Thin Films, edited by E. R. Myers and A. I.Kingon (Mater. Res. Soc. Proc. 200, Pittsburgh, PA, 1990); (b) Ferroelectric Thin Films II, edited by A. I.Kingon, E. R. Myers and B. A. Tuttle (see Ref. 2(a), 1992); and (c) Ferroelectric Films, see Ref. 1.

3. K. Chen and J. Mackenzie in Better Ceramics Through Chemistry IV, edited by B. J. J. Zelinsky, C. J. Brinker, D. E. Clark, and D. R. Ulrich (Mater. Res. Soc. Proc. 180, Pittsburgh, PA, 1990) pp. 663-668.

4. S. H. Rou, T. M. Graettinger, A. F. Chow, C. N. Soble, Il D. J. Lichenwalner, O. Auciello, and A. I. Kingon, see Ref. 2(b), pp. 81-91; D. Barrow, C. V. R. Vasant Kumar, R. Pascual, and M. Sayer, ibid. pp. 113-122; C. Peng and S. B. Desu, ibid., pp. 335344.

5. L. N. Chapin and S. A. Myers, see Ref. 2(b), pp. 153-58.

6. C. C. Hsueh and M. L. Mecartney, J. Mater. Res. 6, 2208 (1991).

7 B. A. Tuttle, T. J. Headley, B. C. Bunker, R. W. Schwartz, T. J. Zender, C. L. Hernandez, D. C. Goodnow, R. J. Tissot, J. Michael, and A. H. Carim, J. Mater. Res. 7, 1876 (1992). 
8. C. K. Kwok and S. B. Desu, J. Mater. Res. 8, 339 (1993).

9. R. W. Schwartz, R. A. Assink, and T. J. Headley, see Ref. 2(b), pp. 245-254.

10. B. A. Tuttle, J. A. Voigt, D. C. Goodnow, D. L. Lamppa, T. J. Headley, M. O. Eatough, G. Zender, R. D. Nasby, and S. M. Rodgers, J. Amer. Ceram. Soc. 76 (6), 1573 (1993).

11. T. J. Headley, B. A. Tuttle, and J. A. Voigt (unpublished).

12. R. W. Schwartz, B. C. Bunker, D. Dimos, R. A. Assink, D. R. Tallant, I. Weinstock, and D. M. Haaland in Proc. of 3rd Int. Symp. on Integrated Ferroelectrics, (1991) pp. 535-46.

13. G. Yi , Z. Wu, and M. Sayer, J. Appl. Phys. 64 (5), 2717 (1988).

14. B. A. Tuttle, J. A. Voigt, T. J. Garino, D. C. Goodnow, R. W. Schwartz, D. L. Lamppa, T. j. Headley, and M. O. Eatough in Pro. of the 8th IEEE Int. Symp. on Appl. of Ferroelectrics, edited by M. Liu, A. Safari, A. I. Kingon, and G. Haertling (IEEE, Piscataway, NJ, 1992) pp. 344-48.

15. W. A. Johnson and R. F. Mehl, Trans. Metall. Soc. AIME, 135, 416 (1939).

16. M. Avrami, J Chem. Phys., 7 (12), 1103 (1939); 8 (2), 212 (1940); 9 (2) 177 (1941).

17. G. J. Exarhos and M. Aloi, Thin Solid Films 193/194, 42 (1990).

18. G. J. Exarhos and W. M. Risen, Jr., J. Amer. Ceram. Soc. 57 (9), 401 (1974).

19 A. S. Shaikh and G. M. Vest, J. Amer. Ceram. Soc. 69 (9), 682 (1986).

20. S. Rangantahan and M. Von Heimendahl, J. Mater. Sci., 16, 2401 (1981).

21. F. Edelman, Y. Komen, S. S. Iyer, J. Heydenreich, and D. Baither, Thin Solid Films, 222, 57 (1992). 

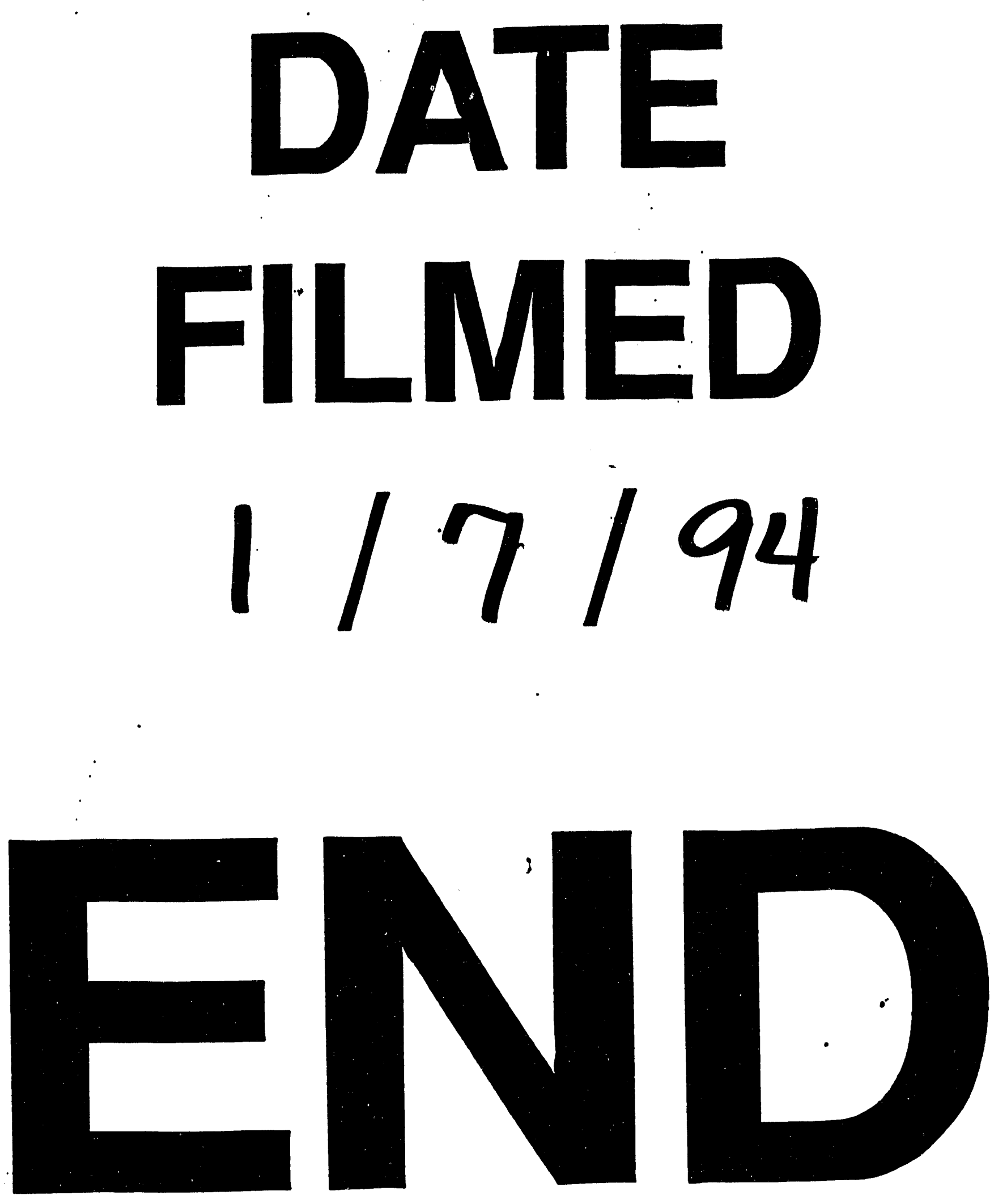
